\title{
Paisagens em desaparição. Cinema em Pernambuco e a relação com o espaço
}

\section{Ângela Freire Prysthon}

\section{Resumo}

0 cinema realizado em Pernambuco vem afirmando de maneira enfática sua preocupação com o espaço, especialmente através de ficções e documentários que elaboram as transformações na paisagem da região e nas cidades (sobretudo o Recife). Este ensaio pretende analisar essa relação com o espaço no cinema contemporâneo realizado em Pernambuco a partir de quatro filmes: Avenida Brasília Formosa (2010), de Gabriel Mascaro, 0 som ao redor (2012), de Kleber Mendonça Filho, Eles voltam (2013), de Marcelo Lordello, e Brasil S/A (2014), de Marcelo Pedroso. São filmes de naturezas, texturas e gêneros distintos, mas que parecem ter em comum a produção de imagens de transição, as quais registram a desaparição de formas de vida, as mudanças na paisagem e as ruínas tanto dos velhos modos de vida, como das novidades do capitalismo predatório, que, de certo modo, já nascem obsoletas. Um dos nossos objetivos é também discutir qual é o papel do que podemos chamar de "imagens de desaparição" (de paisagens, de cidades, de pessoas, de hábitos) na constituição e afirmação do cinema regional no Brasil.

\section{Palavras-Chave}

Paisagem. Desaparição. Cinema contemporâneo.

Ângela Freire Prysthon | prysthon@gmail.com Doutora em Teoria Crítica pela University of Nottingham, Inglaterra. Realizou estágio sênior pós-doutoral no departamento de Film Studies da University of Southampton, Inglaterra. Professora do Bacharelado em Cinema e do Programa de Pós-Graduação em Comunicação da Universidade Federal de Pernambuco - UFPE, Brasil.
0 cinema de Pernambuco vem ocupando um espaço bem relevante na história do cinema brasileiro desde os anos 1920, quando foi estabelecido o chamado "Ciclo do Recife", passando pelo Super 8 nos anos 1970 e pelo espaço relevante no cinema da Retomada. A partir dos últimos anos da década de 2000, esse lugar vem sendo ampliado com uma produção que delineia de maneira enfática a preocupação com o espaço, especialmente através de ficções e documentários que elaboram sobre as transformações na paisagem da região e nas cidades (sobretudo o Recife).

Este artigo pretende apresentar um panorama dessa relação do cinema com o espaço (na sua acepção mais próxima do conceito expandido de paisagens - incluindo o campo e a cidade) em Pernambuco, tentando ver nas imagens sugeridas por uma gama variada de filmes e épocas os rastros de formas de vida quase extintas, as mudanças na paisagem, as ruínas de outros mundos e sua permanência no presente. Um dos nossos objetivos é também discutir qual é o papel do que podemos chamar de "imagens 
de desaparição" (de paisagens, de cidades, de pessoas, de hábitos) na constituição e afirmação do cinema regional no Brasil a partir, principalmente, de quatro filmes da década de 2010: Avenida Brasília Formosa (2010), de Gabriel Mascaro, 0 som ao redor (2012), de Kleber Mendonça Filho, Eles voltam (2013), de Marcelo Lordello, e Brasil S/A (2014), de Marcelo Pedroso.

\section{Paisagens e regionalismo}

Algumas das primeiras imagens do cinema foram do mundo natural em movimento, cenas de rua e vistas de temas topográficos. Nesse sentido, 0 cinema poderia ser interpretado nesses primeiros tempos quase como um subproduto da indústria turística ou do registro geográfico. Parecenos, então, evidente a associação entre filme e paisagem. Encontramos em John Brinkerhoff Jackson uma das possíveis definições de paisagem: "uma porção de terra que o olho pode compreender à primeira vista" $(1984,1)$. Ora, 0 cinema está constantemente nos apresentando porções, pedaços de terra, enquadramentos que organizam e modelam nossos modos de compreender, processar e sentir o espaço. De vários modos, as paisagens fílmicas, mesmo naqueles filmes mais marcados por um projeto narrativo, terminam, por vezes, a ocupar uma centralidade inesperada, ou como aponta Kracauer com relação às "pequenas unidades" de existência material contingente (rostos, espaços, detalhes) capturadas pela imagem fílmica, tais unidades "abrem uma dimensão muito mais ampla do que aquela dos enredos que elas sustentam" (Kracauer, 1997, 303).

0s filmes, em especial aqueles mais claramente ligados ao registro de imagens do mundo natural e mesmo dos entornos urbanos, dariam forma às nossas percepções espaciais, constituir-se-iam em "paisagens" em um modo similar às das artes pictóricas mais tradicionais, principalmente a pintura. Contudo, é importante diferenciar o paisagismo cinematográfico do pictórico convencional, não apenas pelo movimento (diferença já evidente desde os primórdios do cinema), mas também pela presença do som. 0s modos de enquadramento dos territórios e espaços (naturais ou construídos) caracterizam e revelam os elos entre mise en scène e paisagem.

As relações entre paisagem e cinema são permeadas por nuanças que têm tanto a ver com a própria pluralidade do conceito (o qual fica ainda mais evidente quando nos confrontamos com as derivações do termo em inglês: landscape, cityscape, townscape, soundscape, etc), como pela centralidade da paisagem na composição de atmosferas e moods fílmicos, na construção de texturas. Alguns cineastas e autores buscam, deliberadamente, adensar o papel da paisagem no cinema para além de sua função decorativa ou contextual. Para estes, a paisagem cinematográfica se revelaria como uma instância de crítica do espaço (Keiller, 2013, p. 147), ou, mais ainda, como um método de filmar, como um elemento 
primordial de encenação. Naturalmente, alguns gêneros cinematográficos são mais propícios que outros a essa conexão com a paisagem: 0 western, o road movie, o travelogue documentário, o épico, o filme de época. Pensemos, por exemplo, em como as phantom rides do primeiro cinema expunham o movimento a espectadores fascinados por essas viagens virtuais. A ideia do trânsito e 0 entusiasmo pela tecnologia (tanto a dos transportes - em geral, locomotivas - usados para as filmagens, como aquela implicada pelo próprio cinema) mesclavam-se à identificação que o público sentia pelos lugares que apareciam na tela, fossem eles espaços familiares ou terras distantes. Pode-se pensar nessa identificação como uma sorte de afeto pelos lugares enquadrados pelo filme. $\mathrm{Ou}$ seja, a paisagem fílmica definida também como uma geografia emotiva (Bruno, 2007, 202).

0 chamado "Ciclo do Recife" - um dos ciclos

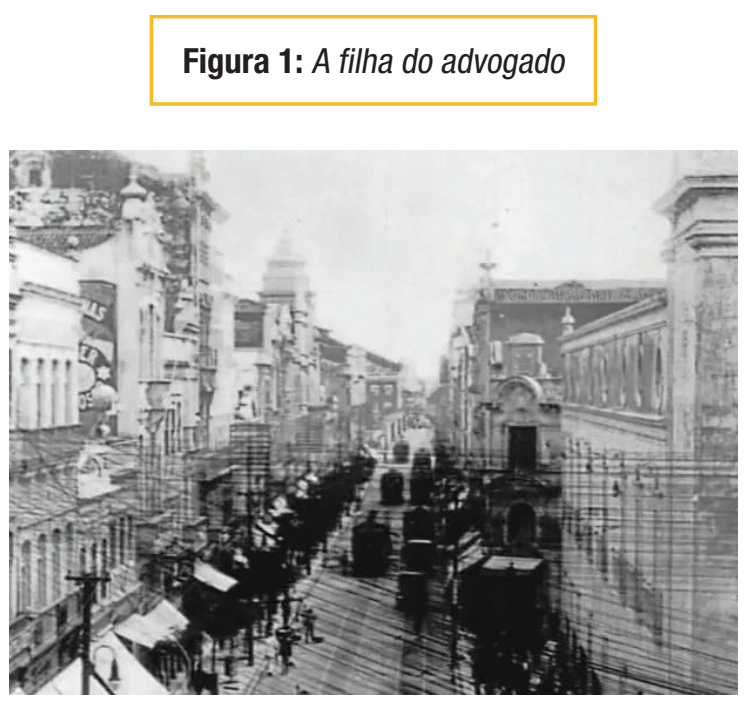

regionais mais destacados do cinema silencioso no país e resultado de um esforço coletivo de cerca de 30 cineastas que, de 1923 a 1931, realizariam 13 longas-metragens (nomes como Edson Chagas, Gentil Roiz, Jota Soares e filmes como Retribuição, Jurando vingar, Aitaré da praia e A filha do advogado, talvez o mais conhecido deles) - pode ser pensado, pois, a partir dessa ideia de geografia emotiva. Parecenos relevante que, desde os primeiros filmes realizados em Pernambuco, esteja impressa uma oscilação entre os modos urbanos, as imagens do interior e, bem especialmente, as figurações do litoral. Contrastemos, por exemplo, 0 elogio da modernidade urbana nas cenas no centro do Recife em A filha do advogado (Jota Soares, 1926) com o romantismo evocativo das paisagens tropicais de Aitaré da praia (Gentil Roiz, 1925):

Afetos e emoções que não deixam de estar

Figura 2: Aitaré da praia

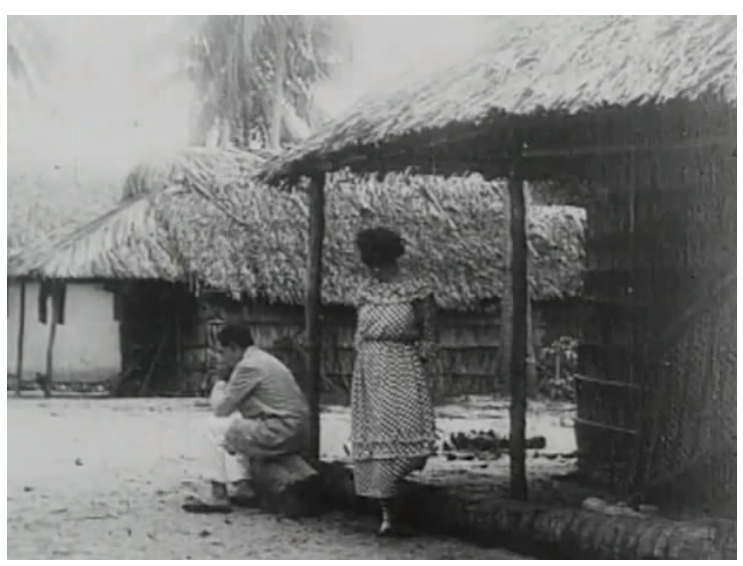


vinculados a modos de poder, a uma geopolítica da paisagem. W. J. Mitchell, por exemplo, alude a certa vocação imperialista da imagem paisagística, referindo-se principalmente à paisagem não apenas como um gênero pictórico, mas como uma formação histórica de tradição europeia (Mitchell, 2002, 5). Nesse sentido também, a paisagem é a cristalização de um modo de olhar, de uma maneira de circunscrever um território e de estabelecer uma espécie de domínio sobre ele. Já nos primeiros filmes realizados em Pernambuco (inclusive os naturaes ${ }^{1}$ ), é possível perceber a noção de paisagem como uma espécie de hieróglifo cultural e social que naturaliza essa forma de olhar.

Embora não seja uma produção pernambucana em um sentido parecido ao dos filmes do Ciclo do Recife, $O$ canto do mar talvez seja o filme que melhor demonstre a construção de geopolítica da paisagem cinematográfica. Foi dirigido em 1953 por Alberto Cavalcanti, cineasta brasileiro radicado na Europa desde os anos 1910, que retorna ao Brasil em 1950 para dar aulas de cinema, formar parte da Vera Cruz e, alguns anos depois, realizar esse grande projeto de cunho regionalista em Pernambuco. 0 canto do mar parece condensar no típico ou em uma acepção exoticizante do espaço suas preocupações paisagísticas, derivando para um pictorialismo que se sobrepõe completamente à narrativa.

Glauber Rocha sugeriu que isso se deveu especialmente à falta de um conhecimento mais profundo sobre a região retratada:

\begin{abstract}
"Cavalcanti, que em seu livro tanto falou na habilidade para a escolha de roteiristas, preteriu um nome vivo como o de José Lins do Rego que tão bem documentou Recife em Moleque Ricardo - pela colaboração raquítica de José Mauro Vasconcelos, paulista, com um suposto conhecimento do Nordeste" (Rocha in Pellizzari e Valentinetti, 1995, 310).
\end{abstract}

Rocha também acusou o filme de uma estilização da paisagem, agravada por deficiências de atuação. 0 que nos parece mais relevante, porém, n'O canto do mar é precisamente a forma como as imagens do sertão árido e inóspito e do litoral urbano acabaram se tornando matrizes centrais não apenas para 0 cinema regional, mas também para toda uma linhagem do cinema brasileiro, a despeito da sua romantização exótica. As imagens lançadas por Cavalcanti (o sertão ressequido, a zona portuária do Recife, as palhoças à beira-mar, os personagens apresentados de modo "sociológico", por exemplo) não eram absolutamente inéditas, mas, combinadas, sintetizaram um padrão paisagístico que viria a perdurar por muito tempo no cinema brasileiro, com ecos, inclusive, no Cinema Novo - ainda que de modo rasurado e negativo. 


\section{Figuras 3 e 4: 0 canto do mar}
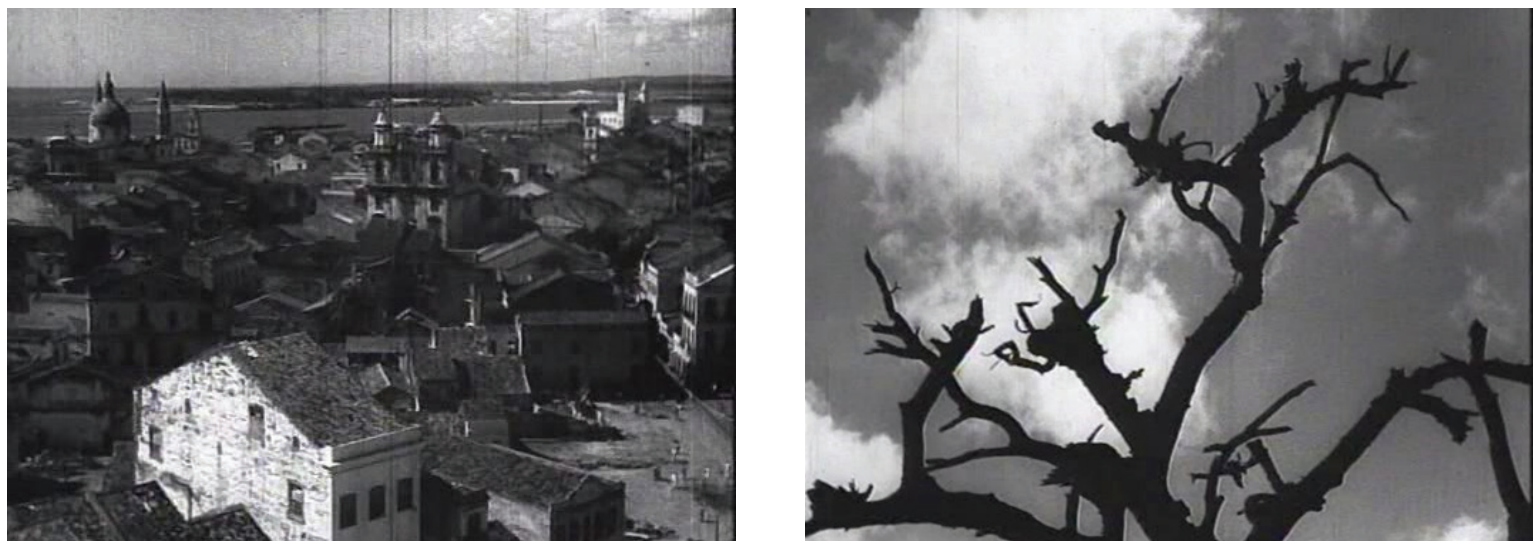

0 cinema em Pernambuco viveu um grande hiato entre o final do Ciclo do Recife e a década de 1970 (entrecortado por alguns documentários institucionais e por um filme de ficção perdido). Emerge, então, o ciclo do Super 8 na década de 1970 para quebrar esse hiato e, de certa maneira, também romper com o padrão do pictorialismo exótico, com nomes como Firmo Neto, Geneton Moraes Neto e Jomard Muniz de Brito, desenvolvendo, sobretudo em Recife, um cinema alternativo e experimental. Do ponto de vista das paisagens, é possível ver em dois filmes de Jomard Muniz de Brito algumas fissuras que acabam por desfigurar a cidade do Recife

e seus emblemas mais célebres. 0 palhaço degolado (1977) é a obra mais conhecida de JMB e nele a cidade, o rio Capibaribe e a Casa de Detenção (atualmente, Casa da Cultura) tornam-se palco para uma feroz performance antitradição. Pode-se ver esse movimento de resistência frente à naturalização folclórica, frente à paisagem colonizada, frente às imagens clichês do Nordeste em toda a obra de JMB, mas n'O palhaço degolado e em Noturno em Ré(cife) maior (1981), as relações com 0 espaço parecem intensificadas e explicitadas. Paisagens conhecidas e espaços familiares da cidade são ressignificados a partir da sátira, da ironia e do estranhamento. 


\section{Figura 5: 0 palhaço degolado}

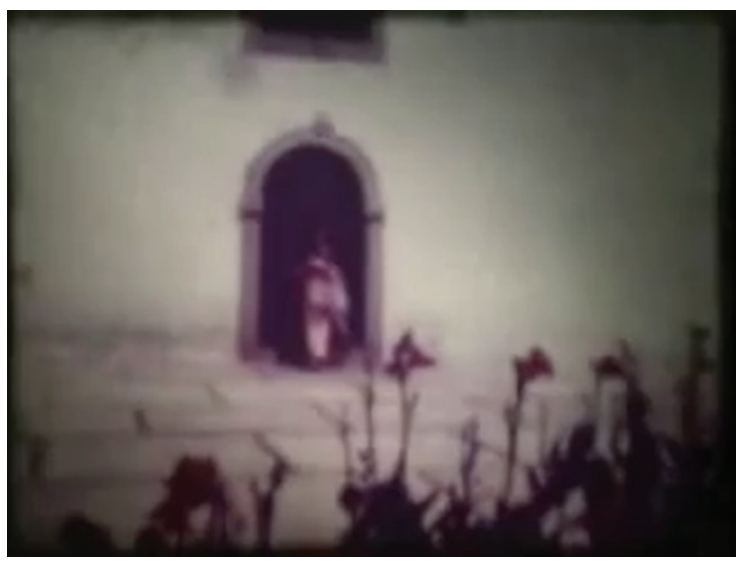

Porém, 0 alcance do Super 8 foi bem pequeno no que se refere à proliferação de paisagens dissonantes no cinema regional. Quase duas décadas após $O$ palhaço degolado, Baile perfumado (Paulo Caldas e Lírio Ferreira, 1996), primeiro longa produzido no estado desde a década de 1970, retomaria e tentaria modernizar a ideia de paisagem monumental implicada n'O canto do mar. Baile perfumado marcou em Pernambuco o que se chamou de "Cinema da Retomada", ou seja, a reconstrução
Figura 6: Noturno em Ré(cife) maior

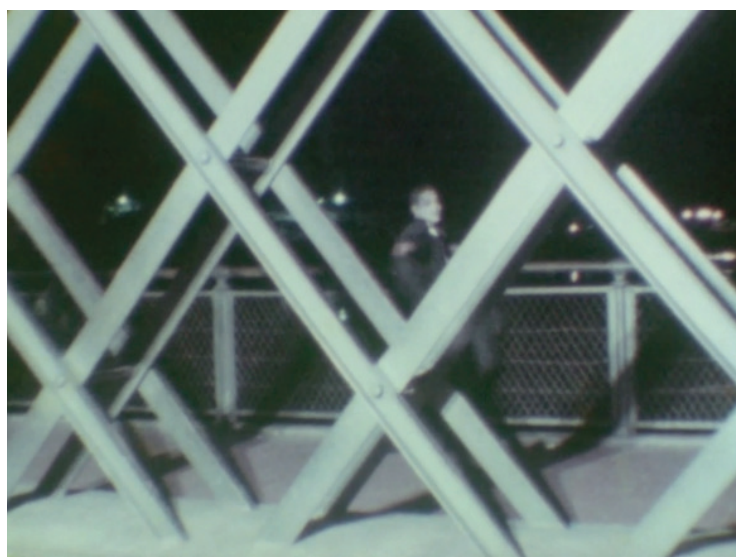

da produção cinematográfica brasileira depois do período de enormes dificuldades entre 0 final dos anos 1980 e início dos 1990. Além de restabelecer a indústria do cinema, a "retomada" significou ainda 0 reconhecimento da produção de outras regiões que não 0 Sudeste, os filmes que vinham de fora do "eixo Rio-São Paulo". Essa emergência de uma filmografia periférica estava associada também a uma afirmação regionalista, mais evidente até na música popular, como no caso do Manguebeat ${ }^{2}$.

Figuras 7 e 8: Baile perfumado
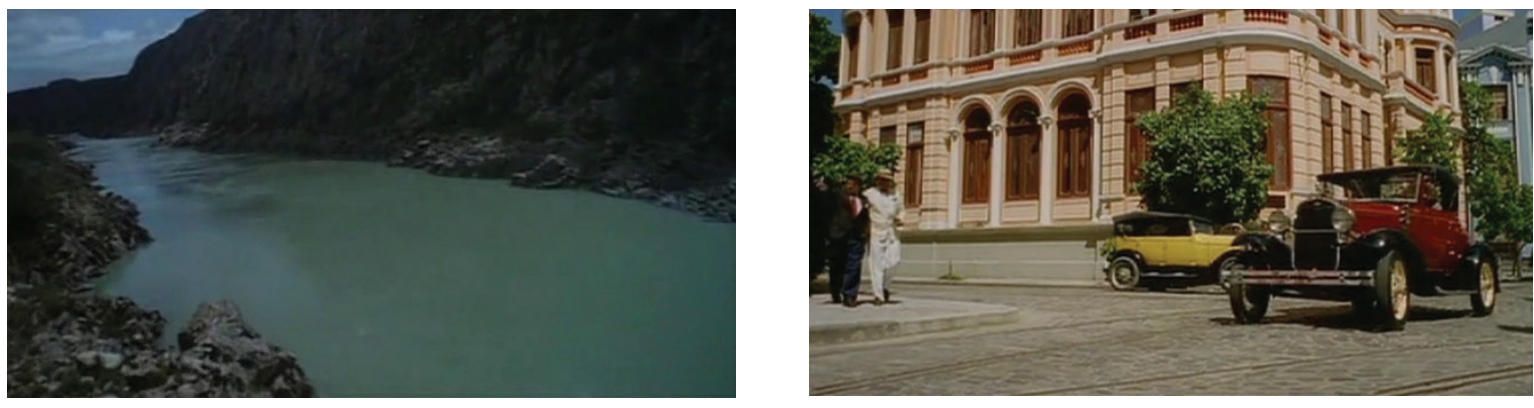

Manguebeat (ou Manguebit, como preferiam seus fundadores) foi um movimento musical do Recife dos anos 1990, com grande influência em outras esferas da cultura como moda, design gráfico e audiovisual. 
É importante sublinhar a ênfase regionalista de grande parte dos realizadores que começaram nos anos 1980 e 1990: de Baile perfumado, de Paulo Caldas e Lírio Ferreira, passando por Amarelo Manga, de Cláudio Assis (2003) (0 taxista que passeia pela cidade, a janela do táxi como uma extensão desse olhar folclorizante); Árido movie (2005), de Lírio Ferreira, e Cinema, aspirina e urubus (2006). Tal ênfase regionalista estava conjugada de modo geral a outro traço estético, um naturalismo que tendia ao grotesco,

\section{Figura 9: Amarelo Manga}

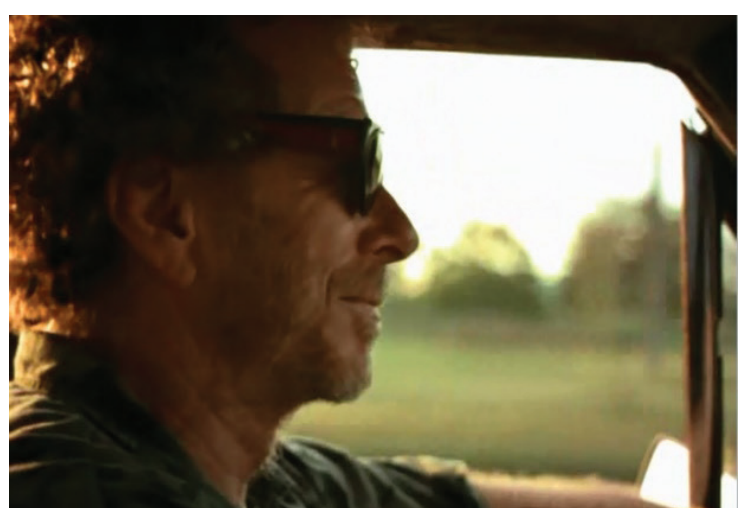

E é justamente a esse localismo folclórico, às paisagens marcadas do sertão, do agreste e da zona da mata, a este excesso grotesco e caricatural do Nordeste, o elogio do popular "histérico" e até certo ponto da vulgaridade ou ao realismo vernacular que, de certo modo, se contrapõe à sensibilidade do banal apresentada pelos cineastas que começam a despontar na primeira metade dos anos 2000 (e, também, por alguns cineastas da geração anterior que tentam matizar o regionalismo, especialmente nas obras de Cláudio Assis e Lírio Ferreira. Sem deixar de ser realista, o cinema mainstream de Pernambuco buscou afirmar uma espécie de sotaque fílmico (Naficy, 2001) através da caricatura, do estranhamento, do excesso de caráter local. Ou seja, recupera-se a matriz pictorialista monumental da década de 1950, mas acentua-se 0 folclórico na mesma medida que se adere a um discurso modernizante e tecnológico (talvez por isso a associação imediata com 0 Manguebeat).

Figura 10: Árido Movie

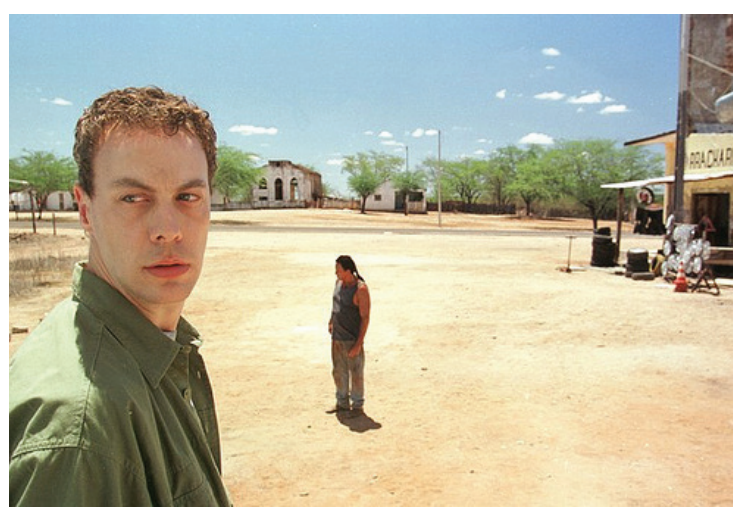

ainda que operando claramente dentro de suas fronteiras - é o caso de Paulo Caldas em Deserto feliz (2007) e, principalmente, Marcelo Gomes, que junto com Karim Ainouz, fez Viajo porque preciso, volto porque te amo (2009). 0 cinema, ainda que não deixando de apresentar características e temas regionais, busca romper com o regionalismo da geração anterior, afastando-se das paisagens do "sertão", abandonando as conexões com 0 manguebeat, evitando o folclore. 


\section{Má arquitetura, ruínas pós-urbanas, paisagens heterotópicas}

Essa "nova geração" de realizadores adveio, sobretudo, da universidade, tendo feito seus primeiros filmes como projetos de TCC na primeira metade da década de 2000. Começaram realizando documentários e curtas-metragens e exibindo seus filmes nos dois principais festivais locais (o Cine $\mathrm{PE}$ - 0 festival mais mainstream da cidade - $\mathrm{e}$ o Janela Internacional de Cinema, evento mais recente e mais alternativo). Outro traço comum é o envolvimento de vários realizadores em questões relativas ao ativismo urbano e ao debate público sobre a cidade. Muitos deles trataram de temas urbanos nesses primeiros filmes, vários deles participaram da obra coletiva Projeto Torres Gêmeas (2011) ${ }^{3}$, e um número expressivo de realizadores também está associado ao movimento Ocupe Estelita ${ }^{4}$.

Se a vinculação à cidade (não apenas Recife, mas a própria noção de cidade) se torna mais explícita e intensa a partir da década de 2010, o foco nos temas urbanos, despidos do tom mais folclórico e regionalista da geração da Retomada, foi uma constante para esses realizadores. Como, por exemplo, para Daniel Bandeira, que no longa Amigos de risco (2008), apresenta uma espécie de versão tropical de After Hours (Martin Scorsese, 1985) de baixíssimo orçamento, o filme mostra as surpresas da vida ordinária, os sustos do cotidiano, o humor melancólico da urbanidade periférica a partir das desventuras de dois amigos de classe média baixa na noite recifense ao se depararem com um terceiro amigo trambiqueiro. Ainda que trazendo à tona a cor local (com os sotaques, os subúrbios e viadutos de Recife, a trilha sonora cheia de sonoridades do tecnobrega local) e se alinhando a certa tradição da representação da violência do cinema brasileiro, parece almejar 0 universalismo da banalidade e 0 apelo dos espaços comuns.

Curta-metragem realizado em colaboração por mais vinte cineastas a partir de uma chamada na internet: "A ideia consiste na realização de um filme coletivo (ainda sem título definido), feito a partir de vários olhares sobre a cidade, nos mais diversos formatos (filme, vídeo, fotografia, ilustração, música, texto escrito etc.) e aberto a qualquer pessoa que deseje participar, independentemente de experiências prévias com 0 audiovisual ou outros meios artísticos." https:// projetotorresgemeas.wordpress.com/

No início de 2012, foi formado um grupo de ativismo urbano contra o desenvolvimento de um projeto imobiliário (Consórcio Novo Recife) no cais José Estelita, no centro do Recife. 0 grupo, chamado Direitos Urbanos, tem se contraposto a um modelo predatório de planejamento urbano e, além de organizar várias ações de ocupação do terreno entre os anos de 2012 e 2014, realizou diversos produtos audiovisuais sobre o tema - nos quais estavam envolvidos vários cineastas proeminentes do estado. 
Figura 11: Projeto Torres Gêmeas

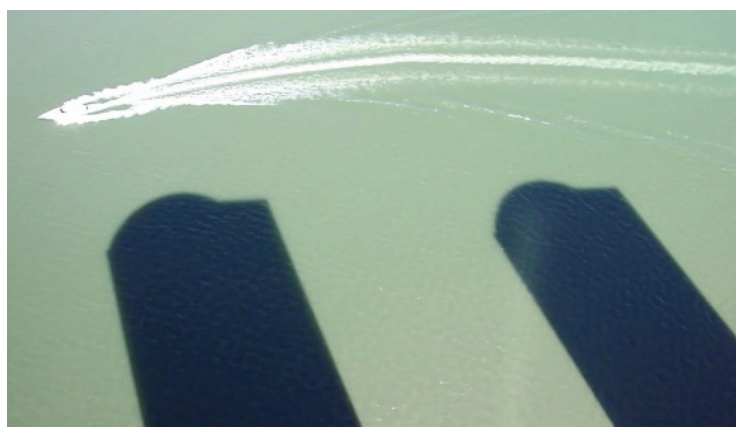

Um dos nomes mais promissores desse novo cinema pernambucano é o de Gabriel Mascaro, que, em 2010, fez Avenida Brasília Formosa (2010), longa-metragem sobre as transformações de uma comunidade pobre da periferia do Recife chamada Brasília Teimosa. Na primeira metade dos anos 2000, foi construída no bairro uma avenida (a do título), uma construção que acabou significando 0 ápice de uma intervenção urbana que deslocou seus moradores para um conjunto habitacional em outro subúrbio da cidade, Cordeiro. Aludindo direta e insistentemente a algumas formas usuais de espetáculo: reality shows, novelas, música brega, música evangélica, Mascaro construiu uma ficção com os moradores do bairro e sobrepôs os registros documentais destes personagens com momentos nos quais eles atuavam e repetiam diálogos escritos pela equipe de roteiristas em locações das suas vidas reais. $0 u$ seja, eles interpretavam a si mesmos nos cenários das suas vidas.
Figura 12: Amigos de risco

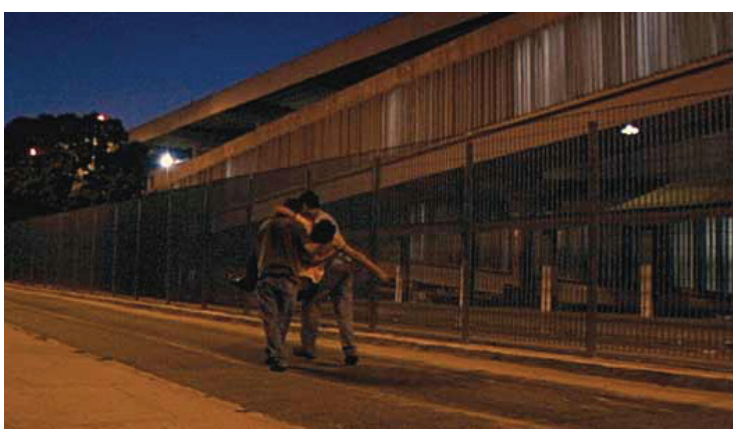

Tratar de desenhar a paisagem a partir desses sujeitos (comuns, completamente inseridos nos espaços retratados, completamente à vontade nesses cenários, nessas locações), todavia, parece-nos a principal característica do filme. Mascaro filma os pescadores que têm que sair do seu bairro litorâneo. Mostra 0 conjunto habitacional desolado para o qual tiveram que se deslocar. Enfoca os espaços através do contraste entre 0 confinamento dos apartamentos do Cordeiro (um conjunto habitacional precocemente decadente pela obsolescência programada prédios que se tornam ruínas em poucos anos de uso) e a vista para o mar de Brasília Teimosa. Uma das cenas mais pungentes é a do trajeto que 0 pescador Pirambu percorre de bicicleta até chegar ao mar, marcada pela melancolia que sublinha a ideia do desaparecimento das paisagens - ainda que estas desapareçam para alguns e permaneçam para outros. 0 passeio do ciclista pescador pela Avenida Guararapes vazia, madrugada adentro no centro do Recife, sugere uma ocupação clandestina da cidade. 0 olhar de Mascaro, ao 
contrário, dos filmes da geração árido movie dos 1990 e 2000, busca desnaturalizar a paisagem e a cidade em lugar de folclorizá-las e torna evidente também a influência do cinema mundial do final dos anos 1990 e início dos 2000, sobretudo de Pedro Costa e Jia Zhang-Ke.

\section{Figuras 13 e 14: Avenida Brasília Formosa}

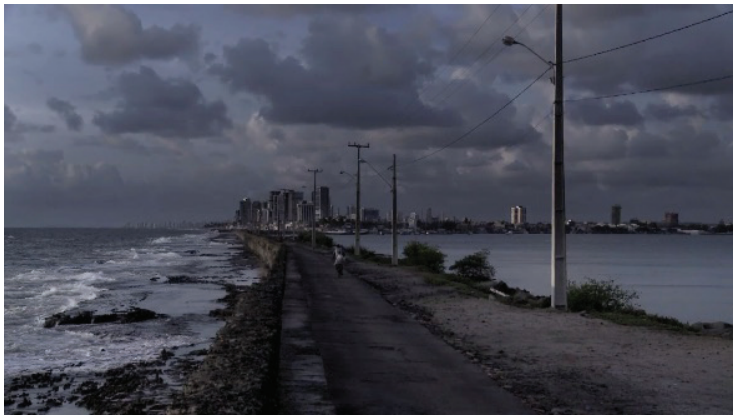

0 realizador de maior expressão a integrar 0 grupo dos novos cineastas pernambucanos, embora seja significativamente mais velho que a maioria deles, é, sem dúvida, Kleber Mendonça Filho, diretor do filme mais célebre do cinema pernambucano antes da explosão de Aquarius (2016), O som ao redor (2012). Mendonça Filho ficou relativamente conhecido no Brasil por seu trabalho anterior como crítico de cinema e pelos seus curtas-metragens (particularmente Vinil verde (2004), e Recife frio (2009), um mockumentary sci-fi).

O som ao redor centra-se em um grupo de residentes no distrito de Setúbal, um enclave de edifícios de classe média em Recife. Ele abre com fotos antigas retratando paisagens das plantações de cana de açúcar em Pernambuco, funcionando quase como uma epígrafe cinematográfica

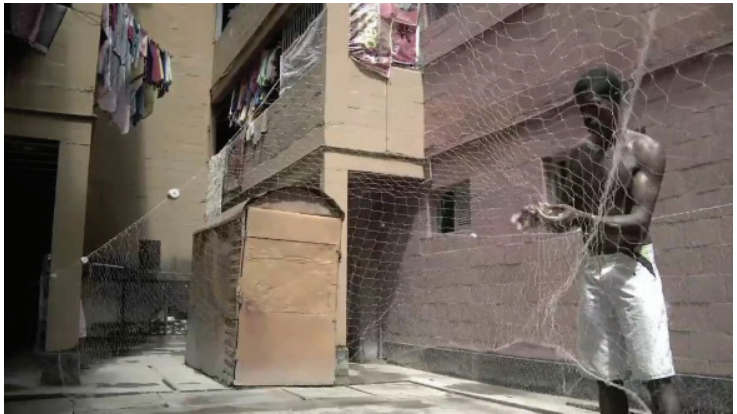

inspirada por Casa Grande e Senzala, tudo isso ao som-canção Cadavres en Serie, de Serge Gainsbourg, o que de saída define um tom pedagógico, entremeado por humor, detalhes banais e observação social. 0 elenco é composto, em sua maioria, por atores não profissionais; as exceções mais notáveis são o patriarca proprietário Francisco, interpretado por W. Solha, a dona de casa Bia, interpretada por Maeve Jenkins, e Clodoaldo, o segurança vivido por Irandhir Santos. Mas nenhum deles é realmente famoso, nem parte do universo das celebridades locais (ao contrário dos filmes da geração anterior com os músicos manguebeat, por exemplo), o que traz uma maior proximidade com a realidade, com o cotidiano do Brasil urbano ordinário.

Contudo, a maior diferença com relação aos filmes regionalistas das décadas de 1990 e 2000 é que 
OSAR não recorre às imagens usuais do Recife (fotos aéreas de suas pontes, cenas em suas ruas mais antigas no centro da cidade com as igrejas coloniais coloridas, edifícios abandonados ou mercados animados e exóticos, como a cidade que vemos retratado em Baile perfumado, Amarelo Manga ou Árido movie). OSAR opta por planos dos arranha-céus monótonos perto da praia de Boa Viagem - como que para provar o comentário de Mendonça que a má arquitetura é muito fotogênica (Sette, 2011) - e interiores anódinos de classe média. A banalidade da crônica de rua e os personagens de vários segmentos sociais diferentes formam a base da visão crítica de OSAR: a cidade, as paisagens de um emergente Nordeste brasileiro e do país como um todo, as ruínas de um passado não distante - sobretudo nas cenas que se passam no interior do estado -, como se esses elementos mínimos fossem os instrumentos diretos para a leitura do contexto mais amplo. Entretanto, evidentemente, suas preocupações não são apenas temáticas. Ele descarta o tratamento cinematográfico convencional em favor de um tempo específico, de um ritmo narrativo particular e de uma atmosfera mais própria ao cinema contemporâneo (que alguns diriam "de festival"), mas, ao mesmo tempo, mantendo alguns traços de estratégias do cinema de gênero (no caso, vários gêneros: vingança, amor, crime, comédia, por exemplo, estão todos presentes, porém em doses muito pequenas).

\section{Figuras 15 e 16: 0 som ao redor}

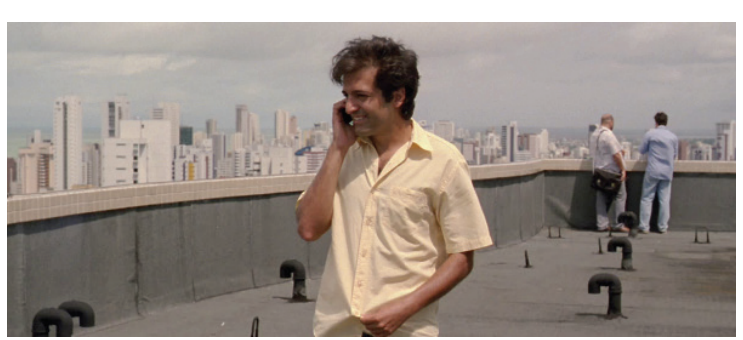

A chave urbana também pode ser encontrada em Marcelo Lordello, que iniciou sua carreira de diretor com o curta-metragem Garotas de ponto de venda (2007), o qual aborda o universo das promotoras de vendas, explorando os não lugares dos interiores dos supermercados recifenses. Lordello vem a aprofundar 0 rechaço ao regionalismo e esboçar, de modo

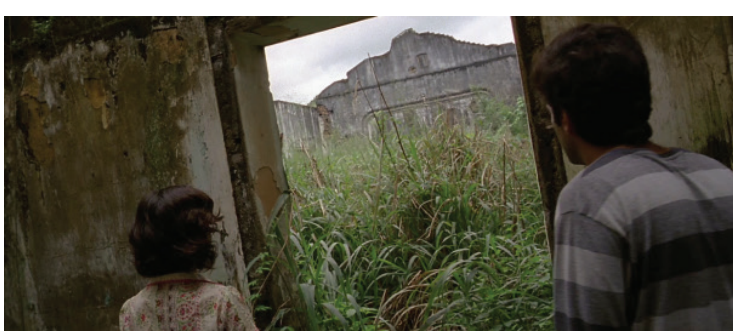

mais contundente, essa poética do banal com outro curta, $N^{\circ} 27$ (2008), desta vez uma ficção sobre um garoto que se tranca no banheiro de uma escola burguesa recifense depois de um ataque de dor de barriga. Através de planos de rigorosa elegância e atuações desafetadas dos adolescentes (quiçá deixando entrever inspirações bressonianas), $N^{\circ} 27$ apresenta 
um acidente do cotidiano que se converte em catástrofe, mostrando o próprio universo do banal como território do horror. No seu primeiro longa-metragem, Vigias (2010), o diretor retoma o documentário e a intenção de registrar as transformações do capitalismo no Recife, ao acompanhar a jornada noturna de sete vigilantes de edifícios de classe média da cidade da sua chegada ao trabalho até a sua saída. Nesse filme, Lordello amplia suas preocupações com os detalhes do cotidiano e dos espaços, com os tempos estendidos e alongados do real, com as minúcias desimportantes da gente comum, frisando, de um lado, a aversão à caricatura e ao barroquismo que predominavam no cinema do Nordeste até a primeira metade da década de 2000 e uma adesão aos ventos minimalistas que sopravam desde a década de 1990, em especial no cinema asiático e latino-americano.

Mas é em seu primeiro longa-metragem de ficção que Lordello irá desenvolver vínculos mais complexos com a noção de paisagem filmica. Eles voltam (2013) tem algumas semelhanças tanto com Avenida Brasília Formosa como com OSAR na sua fusão entre as paisagens urbanas e as imagens do campo.
Mas prevalece a mirada sobre o campo, mais especificamente sobre os imensos canaviais da zona da mata costeira e as pequenas vilas de pescadores e praias do litoral sul de Pernambuco. A sequência inicial (vinte minutos de pouquíssimos planos, quase todos eles do canavial e da estrada) parece querer enfatizar a opção pelo apequenamento da figura humana, pelo plano geral alienante e difuso da paisagem: dois adolescentes, um menino e uma menina, largados em uma estrada, até quase não se perceber onde estão as figuras humanas, já completamente absorvidas pelo entorno.

Lordello infunde sua narrativa de um caráter vagamente fabular, no qual Cris, a adolescente de classe média, funcionaria como uma espécie de Alice no país das maravilhas, descobrindo um mundo para além dos shoppings, conhecendo pessoas "marrons", modos de vida "estranhos" na sua simplicidade absoluta. 0 que nos parece curioso é o modo absolutamente banal em que se dá esse contato. Poucas perguntas são feitas de uma parte a outra, além do que elas são quase desprovidas de contexto, de maiores explicações. A situação é desdramatizada, quase como se

Figuras 17 e 18: Eles voltam
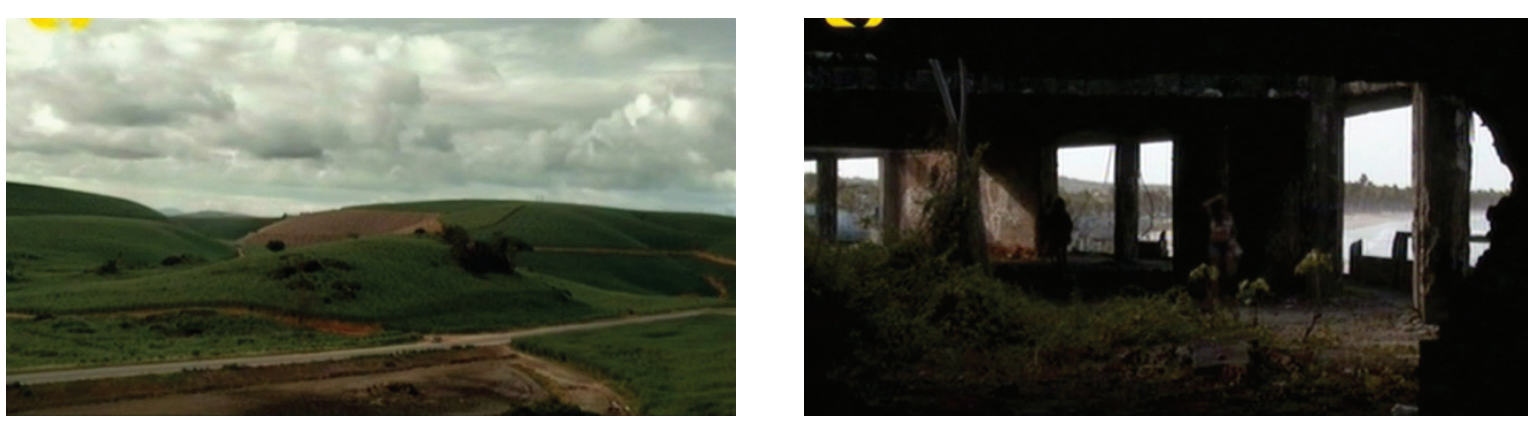
todos estivessem tomados por um leve estupor. Mas, ao mesmo tempo, a menina se abre para ver esses lugares, abraça a descoberta.

Assim como na cena do cinema abandonado em $O$ som ao redor, no filme de Lordello, Cris e sua nova amiga, Jennifer, uma adolescente pobre, visitam as ruínas de um hotel inacabado, sublinhando um tipo de conexão com um passado desconhecido, lugares desconhecidos, história desconhecida. Como Jennifer diz a Cris: "esse lugar estava aqui antes de eu nascer". Também repetindo o padrão de OSAR, as figuras são colocadas junto aos prédios. Como em Amarelo Manga, um táxi passeia pelo Recife, mas diferentemente deste, não é o Recife pitoresco e exótico que está em cena. Antes, é o da obsolescência programada, 0 da má arquitetura, 0 das ruínas precoces.

0 menos urbano dos cineastas apresentados aqui, Marcelo Pedroso começou fazendo trabalhos em parceria com Gabriel Mascaro, como, por exemplo, o documentário de longa-metragem KFZ 1348 (2008), no qual, a partir de um fusca encontrado em um ferro-velho do Recife, mostram a busca por todos os seus oito donos, desde o empresário de São Paulo que o comprou primeiro em 1965 até 0 dono do ferro-velho, percorrendo várias cidades do país. Fez vários documentários em seguida, entre eles o média-metragem Balsa (2009), a filmagem de um dia em uma balsa que leva passageiros e carros de dois pontos distintos do litoral de Alagoas. Incorporando o ritmo do trajeto, ele se aproxima da lentidão observacional de um Jia Zhang-Ke ou de um Lisandro Alonso, deixando irromper um pictorialismo paisagístico quase abstrato.

Paisagens estão também no centro do longa Pacific (2009), documentário que reúne footage feito por passageiros de um cruzeiro de classe média a Fernando de Noronha. 0 documentário engendra narrativas a partir do material preexistente, um material composto por kitsch, sentimentalismo, constrangimento e excesso. Depende completamente de imagens alheias (seu diretor sequer estava no cruzeiro, as imagens foram obtidas por assistentes ao fim da viagem), que primam pela precariedade e pelo clichê amadorístico, porém, uma vez reunidas, ganham um contorno estranho e também melancólico, parecem mostrar 0 avesso do banal dentro da própria banalidade.

Mas é no estranho filme-ensaio Brasil S/A (2014) que Pedroso irá engendrar uma espécie de síntese, de painel exacerbado dos vários problemas sobre 0 espaço no cinema pernambucano contemporâneo. Brasil S/A encampa um modo alegórico de falar sobre a paisagem, sobre a ideia de uma pós-utopia permeando o Brasil. Ele busca reunir todas as questões urgentes da política brasileira como uma espécie de programa, de manifesto. Uma alegoria semifuturística, um apocalipse brando e enigmático: como se fosse impossível escolher entre sonhar uma utopia e representar totalmente o pesadelo de uma distopia. Por isso também, a dificuldade de enquadrar o filme sob o rótulo de 
um gênero, por isso essa sensação de estarmos diante de um documentário freak ou uma ficção científica extremamente entediante e plotless.

Há uma afetação da paisagem, uma dramatização da paisagem, alcançada tanto pelos modos grandiosos de enquadrar esses espaços, como pela pontuação da música pomposa de Mateus Alves. 0 artifício e o deslocamento vão desfigurando as imagens mais corriqueiras do presente, mesmo a arquitetura mais banal da classe média alta recifense. Alguns planossequência poderiam ser reminiscentes do filme Soy Cuba (Mikhail Kalatozov, 1965), no seu afã de demonstrar o progresso (claro que no caso de Brasil
$S / A$ essa demonstração é totalmente irônica) e filmar esse ponto de vista macro, mas em lugar da câmera infravermelha que tornava a textura das paisagens filmicamente peculiares, em Brasil S/A é a mise-en-scène que transfigura os espaços. Por exemplo, nas cenas de canavial, nas quais os trabalhadores usam uniformes parecidos com astronautas ou uma mulher rege uma espécie de balé de tratores (algo que Pedroso já havia ensaiado no seu curta Em trânsito, 2013). A ideia da coreografia das máquinas (caminhões levando tratores pelas estradas) reforça essa oscilação genérica - documentário sob rasura e ficção científica sem ficção.

Figuras 19 e 20: Brasil S/A

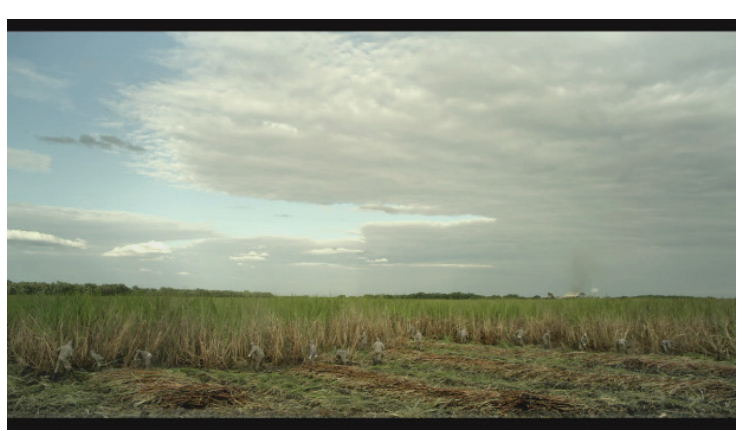

Brasil S/A torna tudo o que é familiar estranho: engarrafamentos no trânsito, cortadores de cana, propaganda de uma empresa de segurança. E até mesmo os personagens de uma dança folclórica nordestina são desfigurados pelo deslocamento, pela afetação: um excêntrico e suado maracatu é encenado na Academia Pernambucana de Letras como um balé europeizado. 0 final se aproxima do

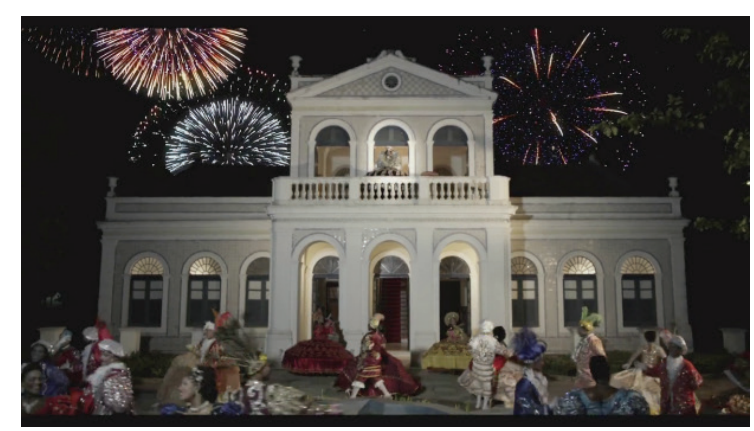

estilo apresentado no filme Nosso lar (Wagner Assis, 2010), filme "espírita" sobre o mundo do além. Uma mistura desse imaginário bregareligioso de Nosso lar com o estilo igualmente brega de propaganda de imobiliária. Uma imagem chapada, feia, rasa. Tão ostensivamente grotesca que talvez também revele algumas limitações técnicas do filme, sobretudo no que se refere aos efeitos especiais. 
Brasil S/A parece apontar para a noção de heterotopia: um lugar que refere e reflete outros lugares, que "tem o poder de justapor em um só lugar real vários espaços, vários posicionamentos que são em si próprios incompatíveis" (Foucault, 2009, 418). Noção esta, aliás, que poderíamos estender à própria presença da paisagem no cinema em geral e no conjunto apresentado neste texto. Essa breve e superficial história da cinematografia regional, os filmes mencionados aqui e o recorte sugerido para analisar as relações entre espaço e imagem são evidentemente apenas uma parte ínfima dos usos e dos modos da paisagem fílmica. No entanto, mesmo esse pequeno conjunto e uma visão tão panorâmica do cinema em Pernambuco deixam explícitas a pluralidade de formas e as constantes mutações da interação entre os sujeitos e seu entorno. Mais do que isso, eles demonstram o quanto as paisagens nos impelem a ver distintamente nossos próprios espaços e nos fazem repensar nosso lugar no mundo.

\section{Referências}

BRUNO, Giuliana. Atlas of Emotion. Londres: Verso, 2002.

FOUCAULT, Michel. "Outros espaços", Ditos e escritos III. Rio de Janeiro: Forense Universitária, 2009, pp.411-422.

HARPER, Graeme e RAYNER, Jonathan (orgs.). Cinema and Landscape. Bristol/Chicago: Intellect, 2010.

JACKSON, John Brinckerhoff. Discovering the Vernacular Landscape. New Haven: Yale University Press, 1984.
KEILLER, Patrick. The View From The Train. Cities \& Other Landscapes. Londres: Verso, 2013.

\section{KRACAUER, Siegfried. Theory of Film: The}

Redemption of Physical Reality. Princeton: Princeton University Press, 1997.

LEFEBVRE, Martin (org.). Landscape and Film. Londres: Verso, 2006.

LOPES, Denilson. No coração do mundo. Rio de Janeiro: Rocco, 2012.

MARTIN, Adrian. Last day Every Day. Figural thinking from Auerbach and Kracauer to Agamben and Brenez. New York: Babel, 2012.

MITCHELL, W. J. T.. "Imperial Landscape", MITCHELL, W. J. (org.), Landscape and Power. Chicago: The University of Chicago Press, 2002, pp. 5-34.

NAFICY, Hamid. An Accented Cinema. Exilic and Diasporic Filmmaking. Princeton: Princeton University press, 2001.

ROCHA, Glauber. "Cavalcanti e a Vera Cruz" in PELLIZZARI, Lorenzo e VALENTINETTI, Claudio. Alberto Cavalcanti. São Paulo: Instituto Lina Bo e P.M. Bardi, 1995, pp. 307-316.

SETTE, Leo. "Filmando ao redor", Cinética, maio, 2011. Disponível em: http://www.revistacinetica.com.br/ entrevistakmf.htm 


\section{Disappearing Landscapes.}

Cinema in Pernambuco and its Relation with Space

\section{Abstract}

The cinema made in Pernambuco has emphatically outlined its concern with space, especially through documentaries and features that elaborate on the changes in the landscapes of the region and cities (mainly Recife). This paper seeks to analyze the relationship between film and landscape in contemporary cinema from four films made in Pernambuco in the last few years: Avenida Brasilia Formosa" (Defiant Brasilia, 2010) by Gabriel Mascaro, O som ao redor (Neighboring Sounds, 2012) by Kleber Mendonça Filho, Eles voltam (They'll come back, 2013) by Marcelo Lordello, and Brasil S/A (2014), by Marcelo Pedroso. Being so different in texture, genre and nature, these films have in common the production of images of transition, that register the disappearance of forms of life, changes of the landscape and the ruins both of old ways of life and the novelties of predatory capitalism - that in some ways are born already obsolete. One of our objectives is also to discuss what is the role of these "images of disappearance" (of landscapes, of cities, of people, of habits) in the constitution and affirmation of regional cinema in Brazil.

\section{Keywords}

Landscape. Disappearance. Contemporary Cinema.

\section{Paisajes en desaparición: El Cine de Pernambuco y su relación con el espacio}

\section{Resumen}

El cine hecho en Pernambuco viene afirmando de manera enfática su preocupación con el espacio, especialmente a través de ficciones y documentales que elaboran las transformaciones en el paisaje de la región y las ciudades (sobre todo Recife). Este ensayo pretende analizar la relación con el espacio en el cine pernambucano contemporáneo a partir de cuatro películas: Avenida Brasília Formosa (2010) de Gabriel Mascaro, $O$ som ao redor (2012), de Kleber Mendonça Filho, Eles voltam (2013), de Marcelo Lordello, e Brasil S/A (2014), de Marcelo Pedroso. Son películas de naturalezas, texturas y géneros distintos, pero que parecen tener en común la producción de imágenes de transición, que registran la desaparición de formas de vida, los cambios en el paisaje y las ruinas tanto de los viejos modos de vida, como de las novedades del capitalismo predatorio que de cierto modo ya nacen obsoletas. Uno de los nuestros objetivos es también discutir cuál es el papel de lo que podemos llamar "imágenes de desaparición" (de paisajes, de ciudades, de personas, de hábitos) en la constitución y afirmación del cine regional en Brasil.

\section{Palabras clave}

Paisaje. Desaparición. Cine Contemporáneo. 


\section{Expediente}

A revista E-Compós é a publicação científica em formato eletrônico da Associação Nacional dos Programas de Pós-Graduação em Comunicação (Compós). Lançada em 2004, tem como principal finalidade difundir a produção acadêmica de pesquisadores da área de Comunicação, inseridos em instituições do Brasil e do exterior.

\section{E-COMPÓS I www.e-compos.org.br I E-ISSN 1808-2599}

Revista da Associação Nacional dos Programas de Pós-Graduação em Comunicação.

Brasília, v.20, n.1, jan./abr. 2017.

A identificação das edições, a partir de 2008, passa a ser volume anual com três números.

Indexada por Latindex I www.latindex.unam.mx

\section{CONSELHO EDITORIAL}

Alda Cristina Silva da Costa, Universidade Federal do Pará, Brasil Alfredo Luiz Paes de Oliveira Suppia, Universidade Estadual de Campinas, Brasil Álvaro Larangeira, Universidade Tuiuti do Paraná, Brasil Ana Carolina D. Escosteguy, Pontifícia Universidade Católica do Rio Grande do Sul, Brasil Ana Regina Barros Rego Leal, Universidade Federal do Piauí, Brasil Ana Carolina Rocha Pessôa Temer, Universidade Federal de Goiás, Brasil Andrea França, Pontifícia Universidade Católica do Rio de Janeiro, Brasil André Luiz Martins Lemos, Universidade Federal da Bahia, Brasil Angela Cristina Salgueiro Marques, Faculdade Cásper Libero, Brasil Ângela Freire Prysthon, Universidade Federal de Pernambuco, Brasil Antonio Carlos Hohlfeldt, Pontifícia Universidade Católica do Rio Grande do Sul, Brasil Arthur Ituassu, Pontifícia Universidade Católica do Rio de Janeiro, Brasil Bruno Campanella, Universidade Federal Fluminense, Brasil Cláudio Novaes Pinto Coelho, Faculdade Cásper Líbero, Brasil Carlos Eduardo Franciscato, Universidade Federal de Sergipe, Brasil Denise Tavares da Silva, Universidade Federal Fluminense, Brasil Eduardo Vicente, Universidade de São Paulo, Brasil Eliza Bachega Casadei, Escola Superior de Propaganda e Marketing - SP, Brasil Elizabeth Nicolau Saad Corrêa, Universidade de São Paulo, Brasil Erick Felinto de Oliveira, Universidade do Estado do Rio de Janeiro, Brasil Erly Vieira Júnior, Universidade Federal do Espirito Santo, Brasil Francisco de Assis, FIAM-FAAM Centro Universitário, Brasil Francisco Elinaldo Teixeira, Universidade Estadual de Campinas, Brasil Frederico de Mello Brandão Tavares, Universidade Federal de Ouro Preto, Brasil Gabriela Reinaldo, Universidade Federal do Ceará, Brasil Gilson Vieira Monteiro, Universidade Federal do Amazonas, Brasil Gustavo Daudt Fischer, Universidade do Vale do Rio dos Sinos, Brasil Igor Sacramento, Fundação Oswaldo Cruz, Brasil Itania Maria Mota Gomes, Universidade Federal da Bahia, Brasil Jiani Adriana Bonin, Universidade do Vale do Rio dos Sinos, Brasil José Afonso da Silva Junior, Universidade Federal de Pernambuco, Brasil
José Luiz Aidar Prado, Pontifícia Universidade Católica de São Paulo, Brasil Juçara Gorski Brittes, Universidade Federal de Ouro Preto, Brasil Laura Loguercio Cánepa, Universidade Anhembi Morumbi, Brasil Liziane Soares Guazina, Universidade de Brasilia, Brasil Luíza Mônica Assis da Silva, Universidade Católica de Brasília, Brasil Maria Ataide Malcher, Universidade Federal do Pará, Brasil Maria Elisabete Antonioli, Escola Superior de Propaganda e Marketing - SP, Brasil Maria das Graças Pinto Coelho, Universidade Federal do Rio Grande do Norte, Brasil Marcel Vieira Barreto Silva, Universidade Federal da Paraíba, Brasil Marcia Tondato, Escola Superior de Propaganda e Marketing, Brasil Marli Santos, Universidade Metodista de São Paulo, Brasil Márcio Souza Gonçalves, Universidade do Estado do Rio de Janeiro, Brasil Mauricio Mario Monteiro, Universidade Anhembi Morumbi, Brasil Mauricio Ribeiro da Silva, Universidade Paulista, Brasil Mauro de Souza Ventura, Universidade Estadual Paulista, Brasil Mayka Castellano, Universidade Federal Fluminense, Brasil Micael Maiolino Herschmann, Universidade Federal do Rio de Janeiro, Brasil Mozahir Salomão Bruck, Pontifícia Universidade Católica de Minas Gerais, Brasil Nísia Martins Rosario, Universidade Federal do Rio Grande do Sul, Brasil Potiguara Mendes Silveira Jr, Universidade Federal de Juiz de Fora, Brasil Raquel Ritter Longhi, Universidade Federal de Santa Catarina, Brasil Regiane Regina Ribeiro, Universidade Federal do Paraná, Brasil Roberto Elísio dos Santos, Universidade Municipal de São Caetano do Sul, Brasil Rodolfo Rorato Londero, Universidade Estadual de Londrina, Brasil Sérgio Luiz Gadini, Universidade Estadual de Ponta Grossa, Brasil Simone Maria Andrade Pereira de Sá, Universidade Federal Fluminense, Brasil Simone Maria Rocha, Universidade Federal de Minas Gerais, Brasil Suzana Reck Miranda, Universidade Federal de São Carlos, Brasil Tarcyanie Cajueiro Santos, Universidade de Sorocaba, Brasil Tatiana Oliveira Siciliano, Pontifícia Universidade Católica do Rio de Janeiro, Brasil Veneza Mayora Ronsini, Universidade Federal de Santa Maria, Brasil

\section{CONSELHO CIENTÍFICO}

Cristiane Freitas Gutfreind, Pontifícia Universidade Católica do Rio Grande do Sul, Brasil Eduardo Morettin, Universidade de São Paulo, Brasil

Felipe Costa Trotta, Universidade Federal Fluminense, Brasil Irene de Araújo Machado, Universidade de São Paulo, Brasil

\section{COMISSÃO EDITORIAL}

Eduardo Antonio de Jesus, Universidade Federal de Minas Gerais, Brasil Marco Antonio Roxo da Silva, Universidade Federal Fluminense, Brasil Osmar Gonçalves dos Reis Filho, Universidade Federal do Ceará, Brasil

\section{CONSULTORES AD HOC}

Kelly C. de Souza Prudencio, Universidade Federal do Paraná, Brasil Francisco P. Jamil A. Marques, Universidade Federal do Paraná, Brasil Tiago Quiroga F. Neto, Universidade de Brasília, Brasil

\section{EQUIPE TÉCNICA}

ASSISTENTE EDITORIAL Márcio Zanetti Negrini REVISÃO DE TEXTOS Press Revisão EDITORAÇÃO ELETRÔNICA Roka Estúdio IMAGEM DE CAPA Silas de Paula

\section{COMPÓS I www.compos.org.br}

Associação Nacional dos Programas de Pós-Graduação em Comunicação

Presidente

Edson Fernando Dalmonte

Programa de Pós-Graduação em Comunicação

e Cultura Contemporânea - UFBA

edsondalmonte@uol.com.br

Vice-presidente

Cristiane Freitas Gutfreind

Programa de Pós-Graduação em Comunicação Social - PUC-RS cristianefreitas@pucrs.br

Secretário-Geral

Rogério Ferraraz

Programa de Pós-Graduação em Comunicação

Universidade Anhembi Morumbi

rogerioferraraz@anhembimorumbi.edu.br

CONTATO I revistaecompos@gmail.com 